\section{Crack Growth Behavior of Sealing Rubber under Static Strain in High-Pressure Hydrogen Gas*}

\begin{abstract}
In order to enable hydrogen society in the near future, it is necessary to clarify the influence of hydrogen on the mechanical, physical and chemical properties of the materials used for hydrogen energy systems. In the case of rubbers, there is a particular danger of mechanical damage resulting from internal fracture, which occurs when high-pressure hydrogen gas is suddenly decompressed. Although our previous studies focused on fracture and deformation caused by high-pressure hydrogen decompression, the fracture and deformation of rubber materials under pressurization have not been studied. From this viewpoint, static crack growth tests of an unfilled sulfur-crosslinked ethylene-propylene-diene monomer (EPDM) rubber were conducted in hydrogen gas at $10 \mathrm{MPa}$ and room temperature (around $25^{\circ} \mathrm{C}$ ) by using a high-pressure hydrogen vessel with glass viewing ports. Deformation of the rubber during pressurization was hardly seen at $\leq 10 \mathrm{MPa}$, although hydrostatic pressure was applied and hydrogen gas penetrated into the rubber. The static crack growth rate for hydrogen gas at $10 \mathrm{MPa}$ was consistent with that in air $(0.1 \mathrm{MPa})$. A lot of facets with about $100 \mu \mathrm{m}$ in size caused by the initiation and successive coalescence of secondary cracks ahead of the main crack were observed on the fracture surface of the specimens tested in air and hydrogen gas at $10 \mathrm{MPa}$, and these fracture surfaces showed a similar aspect. From these results, it was clarified that a hydrogen environment at $\leq 10 \mathrm{MPa}$ did not influence the static crack growth characteristic of the rubber.
\end{abstract}

Key words: Rubber, Elastomer, Hydrogen, Crack Growth, Gas Solubility

\section{Introduction}

In order to enable hydrogen society (or hydrogen economy) in the near future, a number of pressing technical problems must be solved. The materials used in hydrogen energy systems are likely to be exposed to a hydrogen environment, and as iron and steel materials are known to be vulnerable to hydrogen embrittlement, the strength properties of these materials could be adversely affected. However, there are few reports on the effects of hydrogen on the strength properties of organic materials such as rubbers. Organic materials, such as the rubber used for O-rings for sealing high-pressure hydrogen gas vessels, are used together with metallic materials in equipment that is exposed to hydrogen, so it is essential to clarify the effects of hydrogen on the strength properties of both organic and metallic
*Received 21 June, 2011 (No. 11-0333) [DOI: 10.1299/jmmp.5.690]

Copyright (ㄷ 2011 by JSME 
materials. The rubber materials used for O-rings tend to suffer from internal fracture when high-pressure gas is rapidly decompressed ${ }^{(1)}$, which is called a "blister fracture." Although there are many reports on blister fractures caused by high-pressure carbon dioxide, nitrogen, or argon decompression ${ }^{(1)-(10)}$, there are no reports on such fractures caused by highpressure hydrogen decompression. Furthermore, although a lot of studies on internal pressure caused by high-pressure gas decompression have been conducted, the mechanism of internal cracking has not been clarified yet. Before rubber materials are used in hydrogen equipment, it is important to clarify whether hydrogen gas causes blister fractures-as do some other gases - and the mechanism of the internal fracture. We have been studying the influence of fillers, such as carbon black and silica, on the internal fracture and hydrogen permeation properties of EPDM rubber and acrylonitrile-butadiene rubber (NBR) ${ }^{(11)}$, and as a result, we have verified that hydrogen gas causes internal fracture as do some other gases. It was also clarified that carbon black raised the hydrogen gas solubility of rubber due to hydrogen absorption, while silica did not. Furthermore, the degree of internal cracking became more pronounced along with an increase in hydrogen gas solubility and a decrease in material strength. As carbon black raises hydrogen gas solubility, while at the same time reinforcing the rubber, crack damage in carbon black-filled rubbers tended to be more serious than that in silica-filled rubbers.

We also investigated the mechanism of internal cracking thoroughly ${ }^{(12)-(15)}$ using an atomic force microscopy $(\mathrm{AFM}){ }^{(15)}$, a scanning electron microscopy (SEM) ${ }^{(12),(13)}$, an optical microscopy $(\mathrm{OM})^{(12),(13)}$, and acoustic emissions $(\mathrm{AE})^{(14)}$. These results suggested that sub-micrometer-size bubbles were formed in nanoscale inhomogeneous structures in the rubber by high-pressure hydrogen decompression. Some of these bubbles grew to micrometer-size bubbles and consequently caused crack initiation. In this discussion, the bubble is regarded as a cavity less than micrometer size which is hardly observed by OM, while the crack is regarded as a cavity more than micrometer size which can be observed by OM. Based on this mechanism, the critical hydrogen pressure at crack initiation was estimated in terms of the fracture mechanism. The critical hydrogen pressures at crack initiation for several EPDM rubbers were successfully estimated.

In contrast with the internal cracking resulting from the high-pressure hydrogen decompression mentioned above, there have been few studies on the fracture and deformation behavior of polymers under pressurization. Davies et al. conducted tensile tests on several elastomers in a carbon dioxide gas and nitrogen gas environment at $\leq 4 \mathrm{MPa}$. $\mathrm{He}$ reported that the modulus and tensile strength degraded in a carbon dioxide gas environment, but did not degrade in a nitrogen gas environment ${ }^{(16)}$. Castagnet et al. conducted tensile test of polyethylene (PE) and polyamide 11 (PA11) in hydrogen and nitrogen gas at $\leq 3 \mathrm{MPa}$. He reported that neither gases exhibited a noticeable deleterious influence on their tensile properties ${ }^{(17)}$.

On a related point, as sealing rubber O-rings are used under conditions of compression, tensile stress is generated near the center of the core of the O-rings. Cracks sometimes grow under static (constant) strain in rubber materials; therefore, crack growth behavior under static strain (static crack growth behavior) influences the durability of O-rings, as known from the fracture behavior of sealing O-rings ${ }^{(18)}$. If mechanical properties such as modulus and tensile strength are degraded, the static crack growth rate will be accelerated; consequently, the durability of O-rings will be degraded. However, it has not yet been clarified whether a hydrogen environment influences the crack growth behavior of sealing rubber O-rings.

From this viewpoint, static crack growth tests of an unfilled sulfur-crosslinked EPDM rubber were conducted using hydrogen gas at $10 \mathrm{MPa}$ and room temperature $\left(25^{\circ} \mathrm{C}\right)$. A high-pressure hydrogen vessel with glass viewing ports was developed, and measurements of crack length and deformation under pressurization were made. Hydrogen permeation 
tests of the EPDM rubber were also conducted using a hydrogen permeation tester. Then, the influence of the hydrogen environment on the crack growth characteristic of the EPDM rubber was investigated.

\section{Experimental}

\subsection{Material}

We used an unfilled sulfur-vulcanized EPDM rubber, which was a compound of EPDM with $1.0 \mathrm{phr}$ (parts by weight per hundred parts of rubber) of stearic acid, $5.0 \mathrm{phr}$ of zinc oxide, $1.5 \mathrm{phr}$ of sulfur, and $2.9 \mathrm{phr}$ of accelerator. The density and durometer hardness (Type A) were $0.928 \mathrm{~g} / \mathrm{cm}^{3}$ and 54 , respectively. The glass transition temperature obtained from a viscoelasticity test was $-39.2{ }^{\circ} \mathrm{C}$. From this rubber, a sheet specimen with a thickness of $2 \mathrm{~mm}$ was manufactured. The EPDM rubber used in this study was Esprene 505. The mastication and mixing of its rubber were conducted by using a two-roll mill with eighteen inch. Firstly, the mastication of the rubber was conducted for 10 minutes. Then, zinc oxide, sulfur, stearic acid and accelerator were added to the masticated rubber; afterwards, these were mixed for 10-15 minutes. The compounded rubber obtained by mixing was mold and vulcanized under the pressure of $15 \mathrm{MPa}$. The vulcanization of the sheet specimen was conducted at $170{ }^{\circ} \mathrm{C}$ for 10 minutes.

\subsection{Specimen and experimental method}

\subsubsection{Hydrogen permeation test}

The hydrogen permeation properties of the rubbers were measured using a hydrogen permeation tester (GTR Tec Corp., GTR-30AFKU). Hydrogen gas that permeates a sheet specimen with a thickness of $2 \mathrm{~mm}$ was measured under a differential pressure of $0.6 \mathrm{MPa}$. When the hydrogen pressure at a low-pressure side is zero, the hydrogen gas permeability $(Q)$, diffusivity $(D)$ and solubility $(S)$ obtained by the differential pressure method ${ }^{(19)}$ are expressed as follows:

$$
Q=\frac{l}{A p_{1}} \frac{d q}{d t}, \quad D=\frac{l^{2}}{6 t_{D}}, \quad S=\frac{Q}{D}
$$

where, $q$ : the amount of hydrogen gas that permeates the specimen, $t$ : permeation time, $A$ : permeation area, $l$ : thickness of the specimen, $p_{1}$ : hydrogen pressure at a high-pressure side, and $t_{D}$ : delay time.

\subsubsection{Static crack growth test in hydrogen gas}

A static crack growth test in hydrogen gas was conducted using a high-pressure hydrogen vessel with glass viewing ports. Figure 1 shows the shape and dimensions of the specimen as well as the jig used for the static crack growth test. Figure 2 shows the
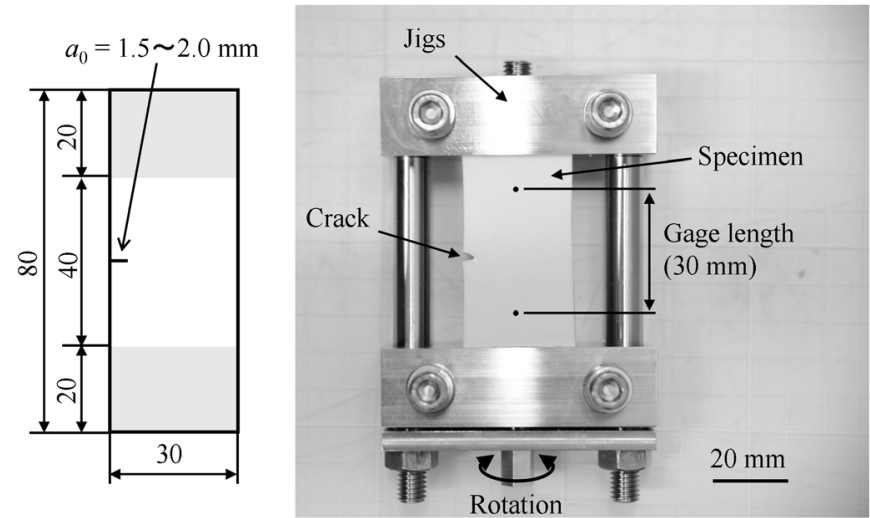

Fig. 1 Shape and dimensions of specimen and jig in $\mathrm{mm}$ for static crack growth test 


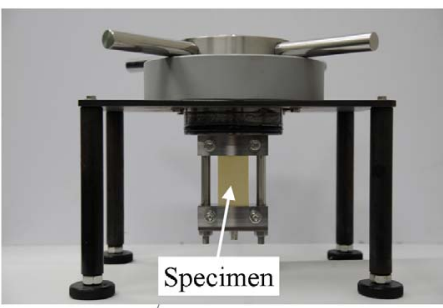

(a-1) Side view of high-pressure vessel

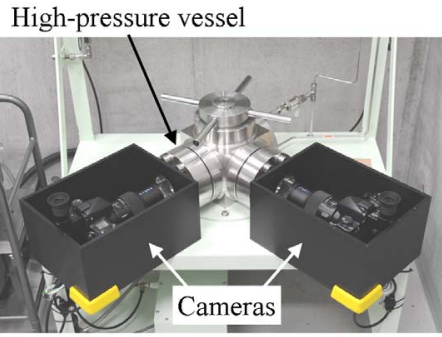

(a-2) Top view of high-pressure vessel

(a) Photograph of high-pressure vessel with glass viewing port

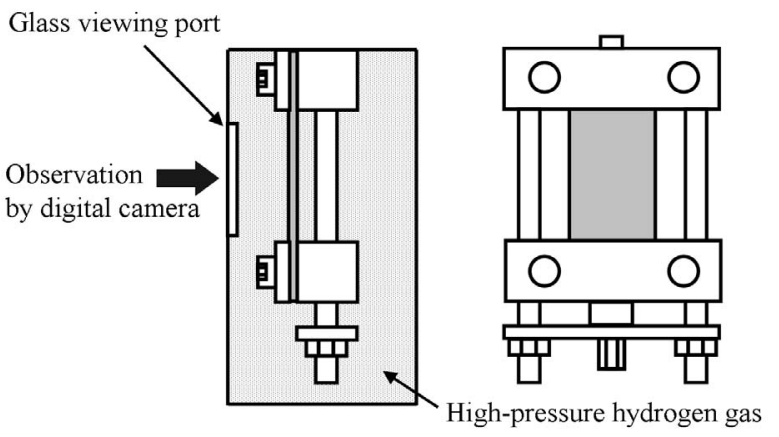

(b) Schematic representation of observation method

Fig. 2 Experimental setup for static crack grow test in high-pressure hydrogen gas environment

experimental setup of the static crack growth test. A cut specimen as shown in Fig. 1 was employed. The specimen was set in the jig, and a constant nominal strain was applied to the specimen at a gage length of $30 \mathrm{~mm}$. The jig was then positioned in the hydrogen vessel shown in Fig. 2 (a). As the crack grows with time, the crack length was measured using a digital camera, as shown in Fig. 2(b). The test was conducted at room temperature (around $25^{\circ} \mathrm{C}$ ). The tearing energy of the specimen was calculated as follows ${ }^{(20)}$ :

$$
\begin{aligned}
& T=2 k(\alpha, \lambda) \cdot W_{0}(\lambda) \cdot a \\
& k(\alpha, \lambda)=\left(-1.6585 \alpha^{2}+0.0191 \alpha+1.0202\right) \\
& \times\left(-6.2865 \lambda^{3}+27.7230 \lambda^{2}-41.9512 \lambda+24.2590\right) \\
& 0.02 \leq \alpha\left(=\frac{a}{h}\right) \leq 0.2,1.05 \leq \lambda \leq 1.50
\end{aligned}
$$

where $T$ : tearing energy $(\mathrm{N} / \mathrm{mm}), \lambda$ : stretch, $W_{0}(\lambda)$ : stain energy density (MPa), $a$ : cut length $(\mathrm{mm}), h$ : specimen width $(\mathrm{mm})$. The stretch $(\lambda)$ was expressed as $\lambda=\varepsilon_{\mathrm{n}}+1$, where $\varepsilon_{\mathrm{n}}$ is nominal strain. Equation 2 was obtained by the finite element method (FEM). In this study, static crack growth testes were conducted under stretches ranging from 1.10 to 1.15.

The strain energy density was calculated from the nominal stress-stretch curve $\left(\sigma_{\mathrm{n}}-\lambda\right.$ curve) of the smooth specimen without a cut as follows:

$$
W_{0}(\lambda)=\int_{1}^{\lambda} \sigma_{\mathrm{n}}(\lambda) d \lambda
$$

The nominal stress-stretch curve was measured from a type-1 dumbbell specimen (JIS K 6251) obtained from the sheet specimen by using a tensile tester (Shimadzu Corp., Autograph AG-X). The specimen was elongated under atmospheric pressure $(0.1 \mathrm{MPa})$ at room temperature (around $25^{\circ} \mathrm{C}$ ).

The hydrogen content of the specimen used for the static crack growth test was measured using a gas chromatograph mass spectroscopy (J-Science Lab, JSH-201) 


\section{Results and discussion}

\subsection{Nominal stress and nominal strain curve in air}

Figure 3 shows the relationship between nominal stress $\left(\sigma_{\mathrm{n}}\right)$ and nominal strain $\left(\varepsilon_{\mathrm{n}}\right)$ of the EPDM rubber tested in air. The tensile tests were conducted under several tensile speeds $\left(d^{\prime} / d=6.3 / \mathrm{min}, 1.3 / \mathrm{min}, 0.8 / \mathrm{min}, 0.1 / \mathrm{min}\right)$, where $d^{\prime}$ is the cross-head speed and $d$ is the distance of the jigs. While the tensile strength of the EPDM rubber decreased with decreasing tensile speeds, the relationship between $\sigma_{\mathrm{n}}$ and $\varepsilon_{\mathrm{n}}$ obtained at $d^{\prime} / d=0.1 / \mathrm{min}$ and $0.8 / \mathrm{min}$ were on the same curve. Therefore, the strain energy density which is independent of tensile speeds can be obtained from tensile tests at $d^{\prime} / d \leq 0.8 / \mathrm{min}$. In this study, the tearing energy for static crack growth tests was calculated by using the strain energy density obtained from the tensile test at $d^{\prime} / d=0.8 / \mathrm{min}$.

\subsection{Hydrogen gas diffusivity of EPDM rubber}

Figure 4 shows an Arrhenius plot of the hydrogen gas diffusivity of EPDM rubber. As the time taken for solute hydrogen to reach equilibrium $\left(t_{\mathrm{eq}}\right)$ depends on hydrogen gas diffusivity, hydrogen gas diffusivity is an important parameter. As shown in Fig. 4, the temperature dependence of hydrogen gas diffusivity is successfully reproduced by an Arrhenius plot. The static crack growth test was conducted at around $25{ }^{\circ} \mathrm{C}$. The diffusivity at $25^{\circ} \mathrm{C}$ was $8.0 \times 10^{-6} \mathrm{~cm}^{2} / \mathrm{s}$.

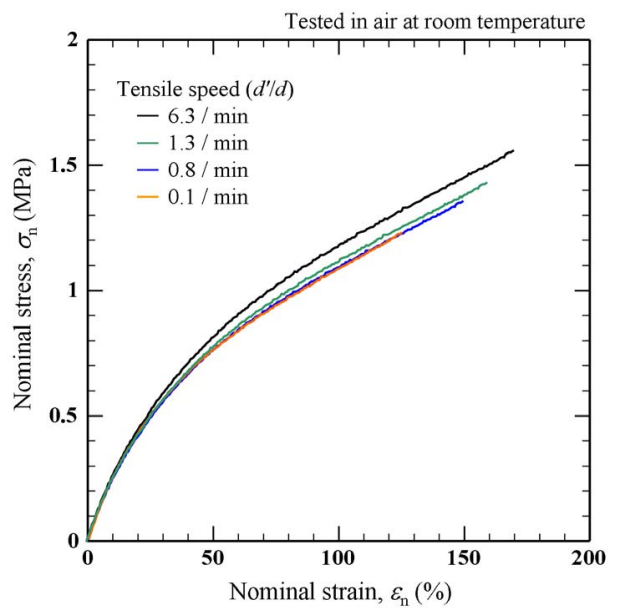

Fig. 3 Relationship between nominal stress and nominal strain of EPDM rubber tested in air

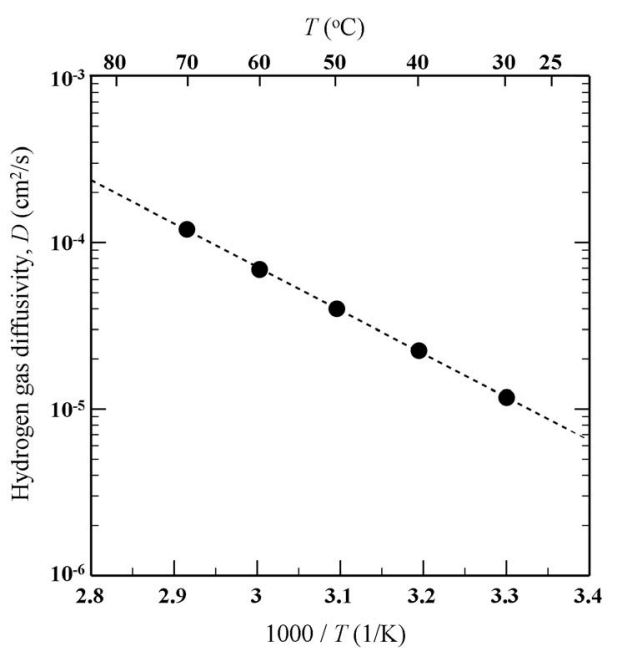

Fig. 4 Arrhenius plot of hydrogen gas diffusivity of EPDM rubber 


\subsection{Hydrogen content of specimen for static crack growth test}

The hydrogen content of the specimen used for the static crack growth test was measured by changing the exposure time. In these measurements, the specimens were exposed to hydrogen gas, and then measurements were commenced about 7 minutes after decompression using a gas-chromatograph mass spectroscopy. Figure 5 shows the relationship between normalized hydrogen content, $c_{E}(t) / c_{0}$, and exposure time, $t$, of the specimen, where $c_{E}(t)$ is the hydrogen content in the specimen (wt.ppm) at exposure time $t$ and $c_{0}$ is the equilibrium hydrogen content (wt.ppm). The hydrogen content reached equilibrium within 1 hour, since $c_{E}(t) / c_{0} \approx 1$ at $t \geq 1$ hour.

In addition to the experimental measurement of hydrogen content, we estimated the relationship between $c_{E}(t) / c_{0}$ and $t$ of the specimen by calculation. When hydrogen gas dissolves in a disc specimen with a radius of $r_{0}$ and a thickness of $z_{0}$, the hydrogen content in the specimen at time $t$ can be obtained as follows ${ }^{(21)}$ :

$$
\frac{c_{E}(t)}{c_{0}}=1-\frac{32}{\pi^{2}} \cdot \times\left\{\sum_{n=0}^{\infty} \frac{\exp \left[-(2 n+1)^{2} \pi^{2} D t / z_{0}^{2}\right]}{(2 n+1)^{2}}\right\} \times\left\{\sum_{n=1}^{\infty} \frac{\exp \left[-D \beta_{n}^{2} t / r_{0}^{2}\right]}{\beta_{n}^{2}}\right\}
$$

where, $D$ is the diffusivity, $\beta_{n}$ is the root of the zero-order Bessel function, $z_{0}$ is the thickness of the specimen, and $r_{0}$ is the radius of the specimen. The calculated results at $r_{0}$ $\rightarrow \infty$ and $r_{0}=15 \mathrm{~mm}$ were shown in Fig. 5 for approximately estimating the hydrogen content of the specimen for the static crack growth test. At $r_{0}=15 \mathrm{~mm}$, the value of $2 r_{0}$ is the equal to the width of the specimen for static crack growth test $(30 \mathrm{~mm})$. For a sheet specimen used in this study, the hydrogen hardly enters from the side of the specimen. Therefore, it is presumed that the calculated relationship between $c_{E}(t) / c_{0}$ and $t$ did not depend on the value of $r_{0}$. The experimental data were consistent with the calculated data, although some scatter of the experimental data was seen. From the experimental and calculated results in Fig. 5, we can estimate that the time it takes solute hydrogen to reach equilibrium $\left(t_{\mathrm{eq}}\right)$ is approximately 2000 seconds.

\subsection{Deformation and static crack growth behaviors}

\subsubsection{Deformation of specimen due to hydrogen exposure}

The deformation of the specimen used in the static crack growth test as a result of hydrogen exposure (pressurization) was evaluated (see Fig. 6). Four points on the surface of the unstrained specimen were marked, and the strain resulting from the pressurization was calculated from the change in distance between the marks as follows:

$$
\varepsilon_{\text {pres }}=\frac{1}{2}\left(\frac{\Delta b_{1}}{b_{1}}+\frac{\Delta b_{2}}{b_{2}}\right)
$$

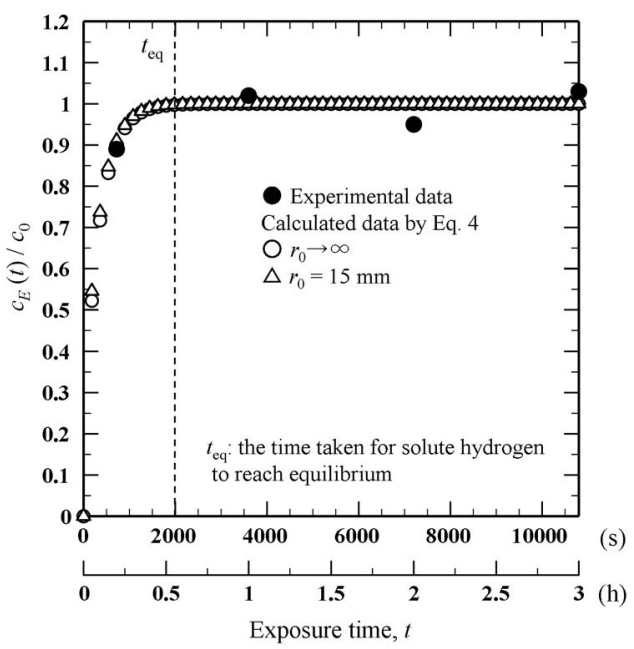

Fig. 5 Relationship between hydrogen content and exposure time of EPDM rubber 
Figure 7 shows the strain of the specimen used in the static crack growth test as a result of exposure to hydrogen at $10 \mathrm{MPa}$. The strain was measured over 24 hours. Although a hydrostatic stress of $10 \mathrm{MPa}$ was applied and hydrogen gas penetrated into the specimen, the strain resulting from the hydrogen exposure was nearly zero. As rubber material is generally incompressible, it is believed that a hydrostatic pressure of $10 \mathrm{MPa}$ hardly influences the deformation of the specimen. Furthermore, rubber material sometimes swells as a result of gas sorption. In our previous studies ${ }^{(22),(23)}$, the volume change in a filled EPDM and an unfilled NBR due to the sorption of hydrogen gas was measured after decompression, not pressurization. As a result, a volume increase in the specimen at $35 \mathrm{MPa}$ and $70 \mathrm{MPa}$ was clearly seen, while one at $\leq 10 \mathrm{MPa}$ was hardly seen, although the hydrogen content dissolved in the specimen increased along with an increase in hydrogen pressure. It is considered that as hydrogen mainly dissolves in the free volume of a rubber structure at $\leq 10 \mathrm{MPa}$, the volume increase was hardly observed at $\leq 10 \mathrm{MPa}$. According to our previous studies, the volume increase in a specimen exposed to hydrogen gas at $10 \mathrm{MPa}$ was estimated to be zero after decompression. For these reasons, it is considered that the strain due to hydrogen exposure at $10 \mathrm{MPa}$ is zero. The $\sigma_{\mathrm{n}}-\lambda$ curve of a swollen specimen differs from that of an unswollen specimen ${ }^{(23)}$. However, hydrogen exposure at $10 \mathrm{MPa}$ hardly influences the volume increase of EPDM rubber, therefore, it was regarded that the $\sigma_{\mathrm{n}}-\lambda$ curve of a specimen exposed to hydrogen gas at $10 \mathrm{MPa}$ was the same as that of one exposed to air, as shown in Fig. 3.

\subsubsection{Static crack growth behavior in air}

Figure 8 shows the relationship between the static crack growth rate and the tearing energy of EPDM rubber in air at room temperature (around $25^{\circ} \mathrm{C}$ ). The crack grow rate was

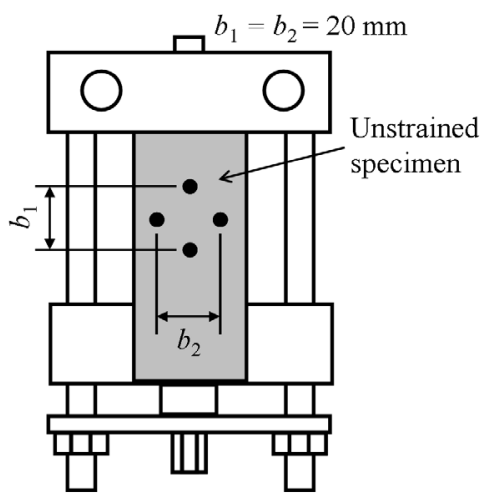

Fig. 6 Method for measuring deformation of specimen under hydrogen exposure

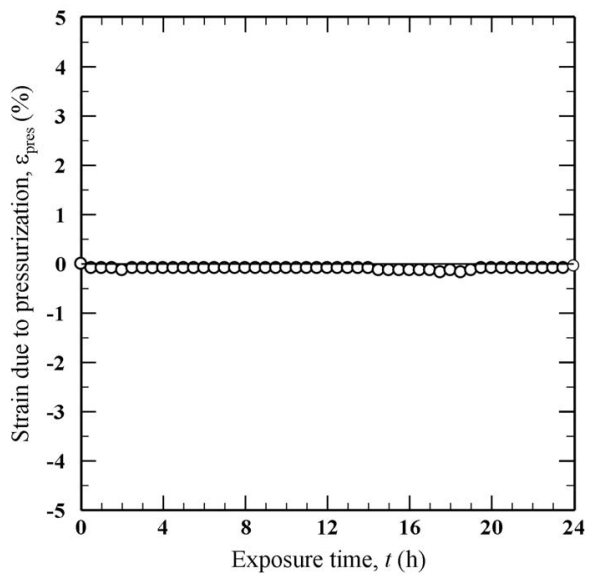

Fig. 7 Relationship between strain caused by hydrogen exposure and exposure time of EPDM rubber in hydrogen gas at $10 \mathrm{MPa}$ 


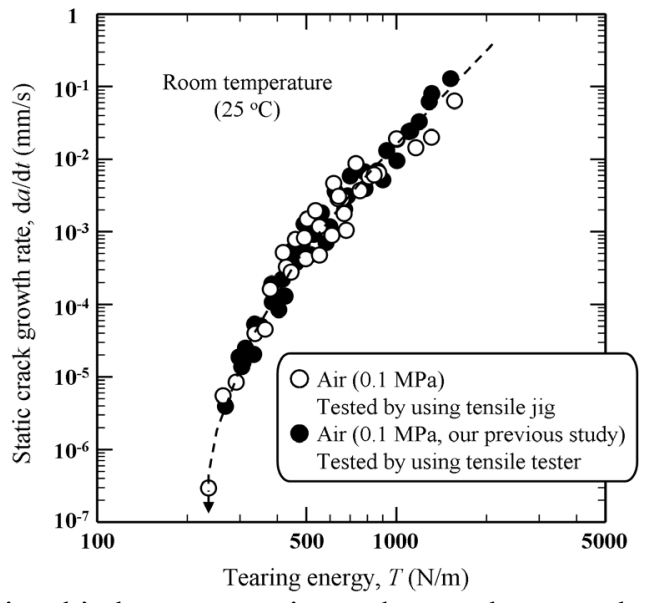

Fig. 8 Relationship between static crack growth rate and tearing energy of EPDM rubber in air at room temperature

calculated when crack growth $(\Delta a)$ meets $\Delta a / a=0.1$. The result obtained using a tensile tester in our previous study ${ }^{(20)}$ is also shown in Fig. 8. The static crack growth rate in this study was consistent with that of the previous study; which showed the static crack growth rate became larger with an increase in tearing energy.

Figure 9 shows optical microscope images of a static crack tested in air. The crack grew in the direction perpendicular to the loading direction macroscopically, although a large degree of surface roughness was seen at the sites near the tip of the crack. Furthermore, a secondary crack was observed ahead of the main crack as known from Fig. 9 (e).

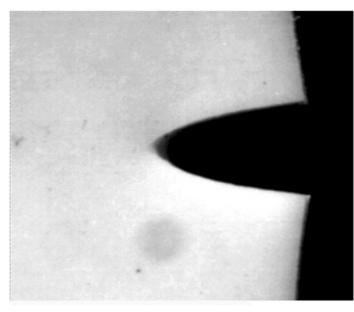

(a) Before test, $a_{0}=1.93 \mathrm{~mm}$

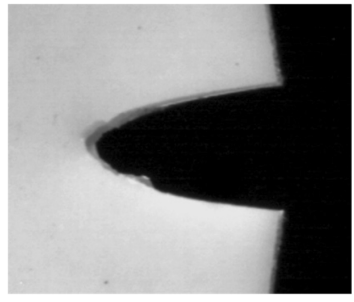

(c) 40 minutes, $a=2.30 \mathrm{~mm}$

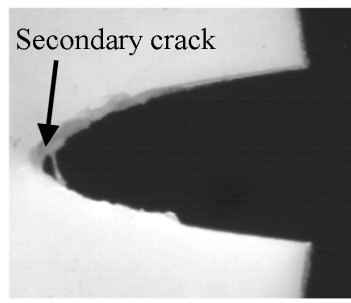

(e) 90 minutes, $a=3.45 \mathrm{~mm}$

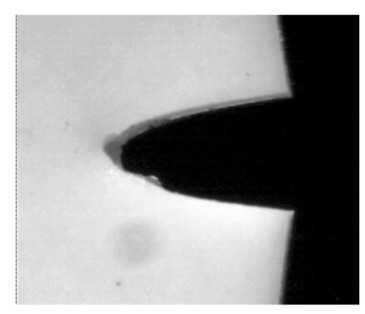

(b) 10 minutes, $a=2.04 \mathrm{~mm}$

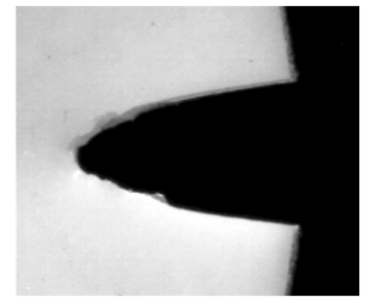

(d) 70 minutes, $a=2.57 \mathrm{~mm}$

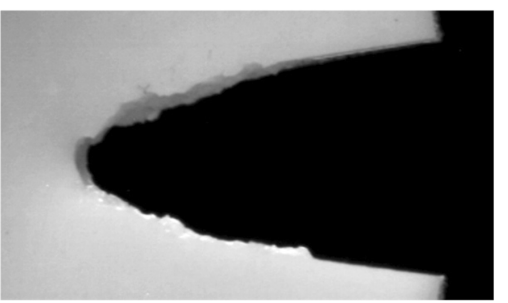

(f) 95 minutes, $a=4.50 \mathrm{~mm}$

$1 \mathrm{~mm}$

Fig. 9 Optical microscope images of static crack of EPDM rubber tested in air at room temperature 
Figure 10 (a) shows a fracture surface of the static crack tested in air by scanning electron microscopy. Figure 10 (b-1) shows the magnification of A in Fig. 10 (a), and Fig. 10 (b-2) shows a schematic illustration of Fig. 10 (b-1). The fracture surface was not flat (see Fig. 10 (a)) and a lot of fracture units (facets) with about $100 \mu \mathrm{m}$ in size were observed (see Figs. 10 (b-1) and 10 (b-2)). The occurrence of the facets on the fracture surface is believed to be due to the initiation and successive coalescence of secondary cracks formed ahead of the main crack. This type of crack growth has been reported in several papers ${ }^{(24),(25)}$.

\subsubsection{Static crack growth behavior in hydrogen gas at $10 \mathrm{MPa}$}

Figure 11 shows the relationship between crack length and the time of the EPDM rubber was exposed to hydrogen gas at $10 \mathrm{MPa}$ at room temperature (around $25{ }^{\circ} \mathrm{C}$ ). The

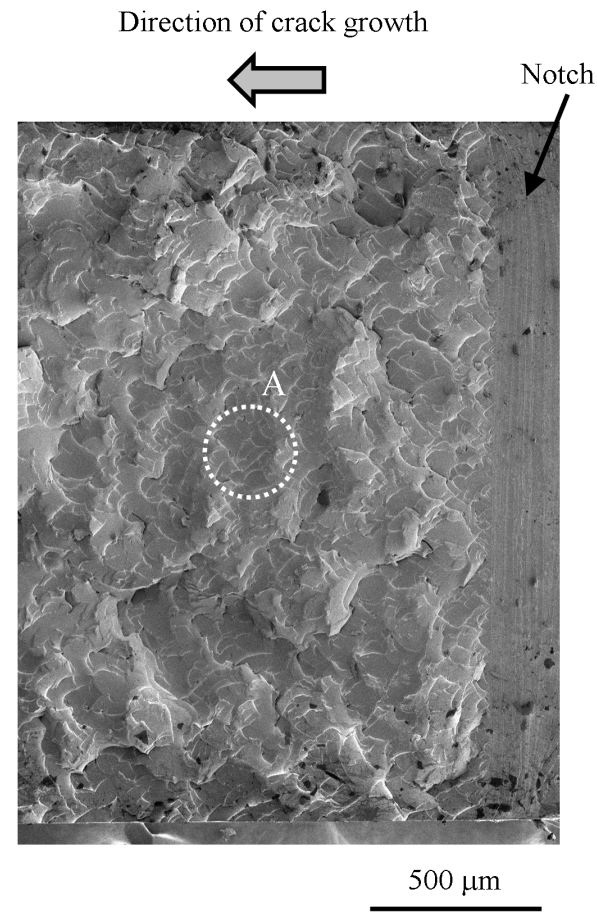

(a)SEM image of fracture surface (low magnification)

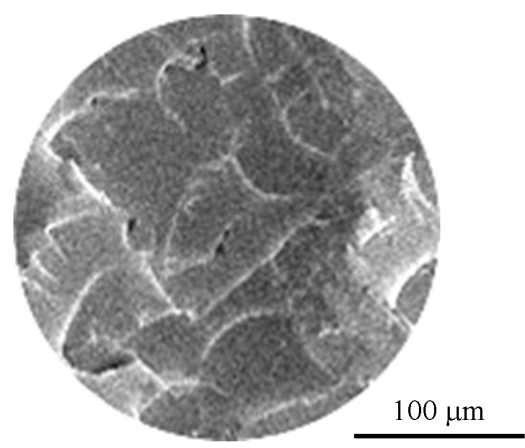

Facet

(b-1) SEM image

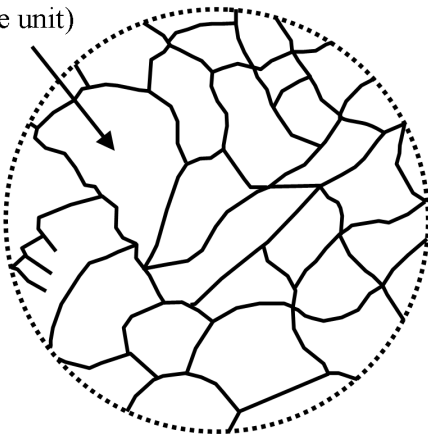

(b-2) Schematic illustration of (b-1)

(b) Magnification of $\mathrm{A}$

Fig. 10 SEM images and schematic illustration of fracture surface of static crack tested in air.

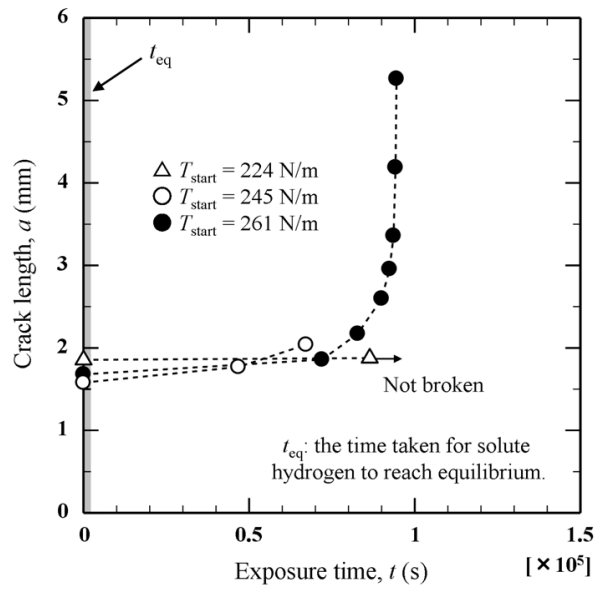

Fig. 11 Relationship between crack length and elapsed time of EPDM rubber tested in hydrogen gas at $10 \mathrm{MPa}$ 
tests in hydrogen gas were conducted at three tearing energies, and it took about 24 hours ( 86400 seconds) to finish the tests. It takes about 2000 seconds (about 0.5 hours) for solute hydrogen to reach equilibrium; therefore, it is presumed that the transition condition of solute hydrogen does not influence static crack growth behavior.

Figure 12 shows the relationship between static crack growth rate and the tearing energy of the EPDM rubber in hydrogen gas at $10 \mathrm{MPa}$ at room temperature (around $25^{\circ} \mathrm{C}$ ). The crack growth rate in hydrogen gas at $10 \mathrm{MPa}$ is consistent with that in air, and signs of an influence from the hydrogen environment on the acceleration of static crack growth are not seen.

Figure 13 shows SEM images of fracture surfaces of the EPDM rubbers tested in air and hydrogen gas at $10 \mathrm{MPa}$. A lot of facets with about $100 \mu \mathrm{m}$ in size were observed on the fracture surface of the specimen tested in hydrogen gas at $10 \mathrm{MPa}$ as well as that of the specimen tested in air, and these fracture surfaces showed a similar aspect. From these results, it was clarified that a hydrogen environment at $\leq 10 \mathrm{MPa}$ did not influence the static crack growth characteristic of EPDM rubber.

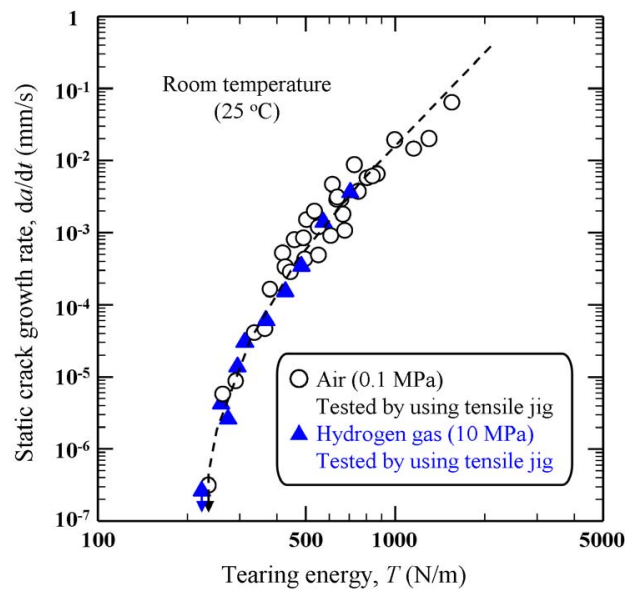

Fig. 12 Relationship between static crack growth rate and tearing energy of EPDM rubber in hydrogen gas at $10 \mathrm{MPa}$ and room temperature

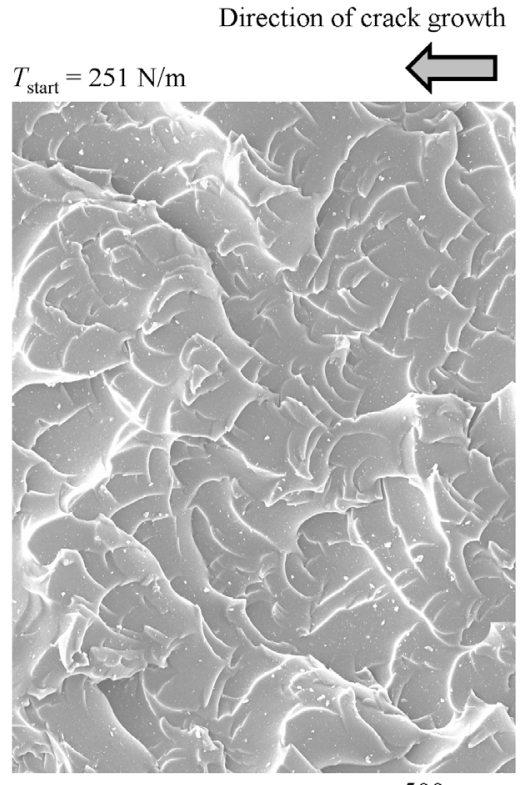

(a) Unexposed specimen

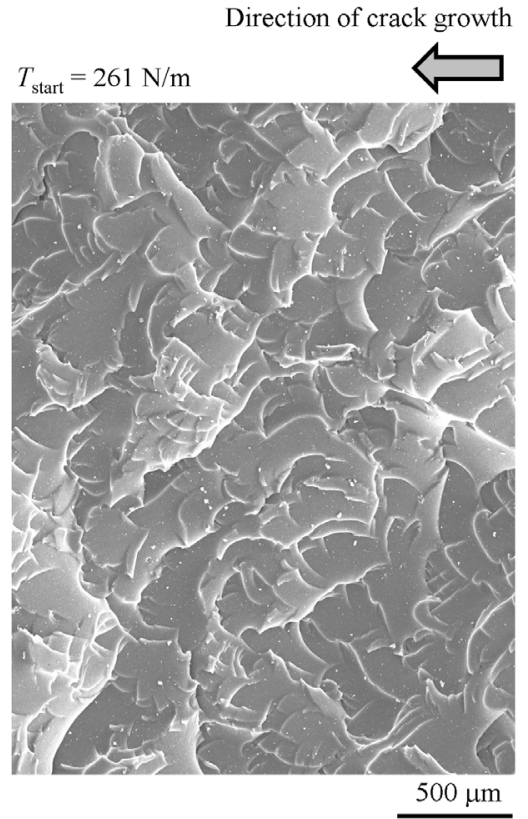

(b) Hydrogen-exposed specimen

Fig. 13 SEM images of fracture surfaces of EPDM rubber tested in air and hydrogen gas at $10 \mathrm{MPa}$ 


\section{Conclusions}

We conducted static crack growth test of an unfilled sulfur-vulcanized EPDM rubber in hydrogen gas at $10 \mathrm{MPa}$ and at room temperature (around $25{ }^{\circ} \mathrm{C}$ ). The influence of hydrogen on the static growth characteristic and deformation due to hydrogen exposure was investigated. The results obtained can be summarized as follows:

1. Even though a rubber specimen was exposed to hydrogen gas at $10 \mathrm{MPa}$, deformation of the specimen was hardly seen.

2. From observation of the static crack of the specimen tested in air by optical microscopy, a secondary crack was observed ahead of the main crack. From observation of its fracture surface by scanning electron microscopy, the fracture surface of the static crack is not flat and a lot of fracture units (facets) with about $100 \mu \mathrm{m}$ in size were observed. The occurrence of the facets on the fracture surface is believed to be due to the initiation and successive coalescence of secondary cracks formed ahead of the main crack.

3. The static crack growth rate of the specimen tested in hydrogen gas at $10 \mathrm{MPa}$ was consistent with that tested in air. A lot of facets with about $100 \mu \mathrm{m}$ in size were observed on the fracture surface of the specimen tested in hydrogen gas at $10 \mathrm{MPa}$ as well as that of the specimen tested in air, and these fracture surfaces showed a similar aspect. From these results, it was clarified that a hydrogen environment at $\leq 10 \mathrm{MPa}$ did not influence the static crack growth characteristic of EPDM rubber.

\section{Acknowledgments}

This research was supported by the NEDO project "Fundamental Research Project on Advanced Hydrogen Science (2006-2012)." We thank Ms. R. Ayaka for obtaining such useful results. The rubbers were manufactured by Takaishi-Industry Co., Ltd.

\section{References}

(1) Briscoe B.J., Savvas T., and Kelly C.T., Explosive decompression failure of rubber: A review of the origins of pneumatic stress induced rupture in elastomer, Rubber Chemistry and Technology, Vol. 67, No. 3 (1994), pp. 384-416.

(2) Gent A.N., and Tompkins D.A., Nucleation and growth of gas bubbles in elastomers, Journal of Applied Physics, Vol. 40, No. 6 (1969), pp. 2520-2525

(3) Gent A.N., and Lindley P.B., Internal rupture of bonded rubber cylinders in tension, Proceedings of the Royal Society, Series A, Vol. 249, No. 1 (1959), pp. 195-205

(4) Lindsey G.H., Triaxial fracture studies, Journal of Applied Physics, Vol. 38, No, 12 (1967), pp. 4843-1967.

(5) Stevenson A., and Glyn M., Fracture of elastomers by gas decompression, Rubber Chemistry and Technology, Vol. 68, No. 2 (1995), pp. 197-211.

(6) Stewart C.W., Nucleation and growth of rubbers in elastomer, Journal of Polymer Science, Part A-2, Vol. 8, No. 6 (1970), pp. 937-955.

(7) Zakaria S., and B.J. Briscoe, Why rubber explodes, Chemtech, Vol. 20, No. 8 (1990), pp. 492-495.

(8) Ender D.H., Elastomeric seals, Chemtech, Vol. 16, No. 1 (1986), pp. 52-56.

(9) Briscoe B.J., and Liatsis D., Internal crack symmetry phenomena during gas-induced rupture of elastomers, Rubber Chemistry and Technology, Vol. 65, No. 2 (1992), pp. 350373.

(10) Epstein P.S., and Plesset M.S., On the stability of gas bubbles in liquid-gas solutions, Journal of Applied Physics, Vol. 18, No. 11 (1950), pp. 1505-1509.

(11) Yamabe J., and Nishimura S., Influence of fillers on hydrogen penetration properties and blister fracture of rubber composites for O-ring exposed to high-pressure hydrogen gas, International Journal of Hydrogen Energy, Vol. 34, No. 4 (2009), pp. 1977-1989. 
(12) Yamabe J., and Nishimura S., Critical hydrogen pressure at crack initiation of silicafilled EPDM composite in high-pressure hydrogen gas (in Japanese), Transactions of the Japan Society of Mechanical Engineers, Series A, Vol. 75, No. 760 (2009), pp.1727- 1737.

(13) Yamabe J., and Nishimura S., Estimation of critical pressure of decompression failure of EPDM composites for sealing under high pressured hydrogen gas, Proceedings of the 18th European Conference on Fracture (2010), CD-DOM

(14) Yamabe J., Matsumoto T., and Nishimura S., Application of acoustic emission method to detection of internal fracture of sealing rubber material by high-pressure hydrogen decompression, Polymer Testing, Vol. 30, No. 1 (2011), pp. 76-85.

(15) Yamabe J., and Nishimura S., Nanoscale fracture analysis by atomic force microscopy of EPDM rubber due to high-pressure hydrogen decompression, Journal of Materials Science, Vol. 76, No. 7 (2011), pp. 2300-2307.

(16) Davies O.M., Arnold J.C., and Sulley S., The mechanical properties of elastomers in high-pressure $\mathrm{CO}_{2}$, Journal of Materials Science, Vol. 34, No. 2 (1999), pp. 417-422.

(17) Castagnet S., Grandidier J.C., Comyn M., and Benoit G., Hydrogen influence on the tensile Properties of mono and multi-layer polymers for gas distribution, International Journal of Hydrogen Energy Vol. 35, No. 14 (2010), pp. 7633-7640.

(18) Yamabe J., Nishimura S., and Koga A., A study on sealing behavior of rubber O-ring in high pressure hydrogen gas, SAE International Journal of Materials and Manufacturing, Vol. 2, No. 1 (2009), pp. 452-460

(19) Van Amerongen G.J., Diffusion in elastomers, Rubber Chemistry and Technology, Vol. 37, No. 5 (1964), pp. 1065-1152.

(20) Yamabe J., and Nishimura S., Influence of vulcanizing agents and hydrogen exposure on static crack growth properties and threshold tearing energy of EPDM for O-Ring (in Japanese), Transactions of the Japan Society of Mechanical Engineers, Series A, Vol. 75, No. 759 (2009), pp. 1531-1541.

(21) Demarez A.L., Hock AG., and Meunier FA., Diffusion of hydrogen in mild steel, Acta Metallurgica, Vol. 2, No. 2 (1954), pp. 214-223.

(22) Yamabe J., Koga A., and Nishimura S., Fracture behavior and hydrogen permeation properties of EPDM for sealing under high pressure hydrogen gas (in Japanease), Nippon Gomu Kyokaishi Vo. 83, No. 6 (2010), pp. 159-166.

(23) Yamabe J., Nakao M., Fujwara H., and Nishimura S., Influence of high-pressure hydrogen exposure on increase in volume by gas absorption and tensile properties of sealing rubber material (in Japanese), Journal of the Society of Materials Science, Japan, Vol. 60, No. 1 (2011), pp. 63-69.

(24) Fukahori Y., and Andrews E.H., Fracture surface roughness in highly deformable polymers, Journal of Materials Science, Vol. 13, No. 4 (1978), pp. 777-785.

(25) Quigley C.J., and Parks D.M., The finite deformation field surrounding a mode I plane strain crack in a hyperelastic incompressible material under small-scale nonlinearly, International Journal of Fracture, Vol. 65, No. 1 (1994), pp. 75-96. 